\title{
De pandemias e compostagens: gerando parentescos sem inocência
}

Pandemics and composting: making kin without innocence

\author{
Fernanda S. Nascimento' (iD 0000-0002-4032-2202 \\ Maria Emilia Sardelich ${ }^{2}$ (i) 0000-0001-8134-8807
}

Universidade Federal de Pernambuco, Núcleo de Formação Docente, Centro Acadêmico do Agreste, Caruaru, Pernambuco, Brasil. 55014-900 - coordpedagogia.

agreste@ufpe.br

${ }^{2}$ Universidade Federal da Paraíba, Centro de Educação, Departamento de Metodologia da Educação, João Pessoa, Paraíba, Brasil. 58051-900-dme@ce.ufpb.br

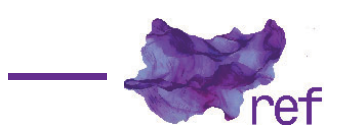

HARAWAY, Donna.

Seguir con el problema. Generar parentesco en el Chthuluceno.

Trad. de Helen Torres. Bilbao: Edición Consonni, 2019. 365p.

Desde o ano de 2020, a pandemia de COVID-19 tem oferecido inúmeras oportunidades para repensarmos os mitos da objetividade científica. O comportamento do Sars-CoV-2 nos fez perceber que nenhuma espécie atua sozinha, pois o vírus modifica sua conduta a depender da habilidade de resposta de seu hospedeiro, maximizando sua virulência em alguns indivíduos e, em outros, a sua transmissibilidade. Convivemos com intoxicantes estatísticas que nos remeteram ao apocalíptico cenário de O Último Homem (Mary SHELLEY, 2007), uma das obras inaugurais do gênero ficção científica, da escritora inglesa Mary Shelley (1797-1851). Por meio da narrativa, mais ou menos, nos identificamos com a desolação que o protagonista Lionel Verney sente com o desmoronamento de uma forma de vida e, também, com a sua resistência. Nesse sentido, a leitura de Seguir con el problema, de Donna Haraway (1944-), alimentou nossa reflexão sobre as possibilidades de gerar um outro mundo, desprendendo-nos da ideia de solução definitiva e salvação.

A bióloga estadunidense Donna Harraway, que se define como uma ecofeminista socialista, branca, de classe média, vem sendo mais conhecida pelas leitoras em português graças às publicações de "O humano numa paisagem pós-humanista" (HARAWAY, 1993), "Saberes Localizados" (HARAWAY, 1995), "Manifesto Ciborgue" (HARAWAY, 2000), "Gênero para um dicionário marxista" (HARAWAY, 2004), "Se nós nunca fomos humanos, o que fazer?" (Nicholas GANE; Donna HARAWAY, 2010), "Companhias multiespécies nas naturezaculturas" (Donna HARAWAY; Sandra AZERÊDO, 2011), "Fragmentos: quanto como uma folha" (HARAWAY, 2015) e "O Manifesto das espécies companheiras" (HARAWAY, 2017). A autora reconhece a profunda influência da ficção científica em seu pensamento que, em sua obra, aparece sob a sigla SF (Science Fiction) e lhe permite especular sobre fatos científicos, vislumbrar cenários possíveis.

Dos oito capítulos que compõem Seguir con el problema, os sete primeiros são versões revisitadas de artigos, editados entre 2012 e 2016, em coletâneas e periódicos estadunidenses, 
franceses e ingleses. Somente o último é inédito. Na longa lista de agradecimentos, indica que a gênese do livro deve-se à sua participação nos cursos organizados por Vinciane Despret e destaca como seu pensamento sobre as geografias, temporalidades e povos humanos e não humanos da nossa época ganhou um novo enfoque a partir do evento Os mil nomes de Gaia', nomeando as contribuições de Deborah Danowski, Eduardo Viveiros de Castro, Juliana Fausto, entre outros. Considera que pensar sobre essas matérias desde "[...] o 'sul global' pode ajudar a desfazer parte da arrogância do 'norte global' [...]"2 (Donna HARAWAY, 2019, p. 16).

Dedica a Introdução para explicar os conceitos e metáforas utilizadas nos vários capítulos. Inicia com a etimologia do vocábulo problema que, em língua inglesa, remete a suscitar, agitar, perturbar. É nesse sentido que a autora reconhece como sendo nossa urgente tarefa provocar as questões que respondam aos acontecimentos devastadores, aprender a estar verdadeiramente presentes como bichos mortais enlaçados em inacabadas configurações de lugares, tempos, matérias e significados. Explica que utiliza o neologismo Chthuluceno a partir das raízes gregas khtôn e kainos que, juntas, denominam um espaço/tempo para seguir com o problema de viver e morrer com responsabilidade em um planeta deteriorado. Para a mitologia grega, os ctônicos são os seres subterrâneos inversos aos deuses olímpicos. Haraway utiliza a grafia chtonicos para esses antigos seres da terra de agora que se recreiam no húmus multibichos. Os chtonicos não estão a salvo, pois todos os monoteísmos do mundo, seja os de disfarce secular ou religioso, vem tratando de exterminá-los. Parente é uma categoria que a autora identifica como selvagem, no sentido de resistir à domesticação que tem sido tentada de modos diferentes. A autora deseja que essa categoria signifique algo mais do que entidades ligadas por ancestralidade ou genealogia. Nesse entendimento, gerar parentesco é reconhecer "[...] como e a quem se é responsável na realidade [...]"3 (HARAWAY, 2019, p. 21). Com essa teia conceitual busca entrelaçar-se com as leitoras por meio do jogo de barbantes, também conhecido no Brasil com as variantes cama de gato, jogo do berço, entre outras. Utiliza essa metáfora para explicitar que o jogo da sobrevivência segue em aberto e, ainda, necessitamos puxar os fios de embaraçadas e embaraçantes práticas sociais para a manutenção da vida. Para produzir as figuras de e com barbante, temos que receber e passar, desfazer e refazer, pegar e soltar os fios seguros pelas diferentes espécies humanas e não humanas.

As palavras-chave do primeiro capítulo, intitulado "Jugando a figuras de cuerdas con especies compañeras" ${ }^{4}$, são: devir com - a transformação permanente do vir a ser que se entretece com os outros - e responsabilidade, entendida como a habilidade de dar resposta. Os argumentos desse capítulo se alastram para o segundo, "Pensamiento tentacular: Antropoceno,

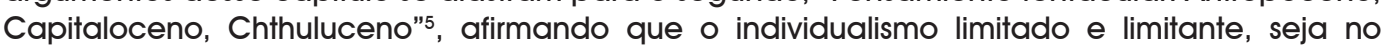
campo político, científico, filosófico, tem demonstrado a incapacidade de estender-se, de pensar com. Para explicar o pensamento tentacular, a autora aplica a metáfora da medusa, desdobrando seus tentáculos para a mitologia grega, psicanálise e zoologia. A medusa, como figura mitológica, é uma das três górgonas, figuras femininas de belos cabelos transformados em ninhos de serpente cuja representação também foi utilizada em forma de talismã. Se a psicanálise relaciona medusa e castração, a zoologia classifica como formas de vida livre, que passam por várias metamorfoses durante o ciclo vital. É desse pensamento tentacular, dessa capacidade de se espalhar e metamorfosear, que necessitamos para responder às ciladas do Anthropos, esse ser que olha para o céu e tem sido incapaz de praticar a curiosidade sem sadismo. Necessitamos respostas às mudanças climáticas, à toxidez da mineração, do esgotamento do solo e das águas, dos genocídios de pessoas e outros seres. Chthuluceno é o nome encontrado para designar as dinâmicas de forças e poderes ctônicos que já estão em curso e que talvez, com intenso compromisso e trabalho colaborativo, seja possível fazer florescer arranjos multiespécies.

No terceiro capítulo, "Simpoiesis. Simbiogénesis y las artes vitales de seguir con el problema"6, Haraway pensa com as ideias da bióloga Lynn Margulis (1938-2011), para quem é a simbiogênese - os efeitos positivos resultantes das interrelações entre os seres - e não a competição pela sobrevivência, que impele o processo evolutivo. Utiliza o vocábulo

\footnotetext{
1 Colóquio Internacional Os Mil Nomes de Gaia: Do Antropoceno à Idade da Terra, Rio de Janeiro, 15 a 19 de setembro de 2014. Disponível em: https://osmilnomesdegaia.eco.br. Acesso em: 10/07/2020.

${ }^{2}$ No original "[...] pensar sobre estas materias desde el 'sur global' puede ayudar a deshacer parte de la arrogancia del 'norte global' [...]".

${ }^{3}$ No original "Generar parientes en parentescos raros más que, o al menos sumándole, el parentesco divino y la familia biogenética y genealógica, problematiza asuntos importantes, como ante quién se es responsable en realidad".

${ }^{4}$ Versão revisada de: HARAWAY, Donna. Jeux de ficelles avec des especes compagnes: rester avec le trouble. In: DESPRET, Vinciane; LARRÈRE, Raphael (edit.) Les animaux: deux ou trois choses que nous savon d'eux. Paris: Hermann, 2014.

5 Versão revisada de: HARAWAY, Donna. Staying with the Trouble: sympoièse, figures de ficelle, embrouilles multiespécifiques. In: STENGERS, Isabelle (edit.). Gestes spéculatifs. Paris: Le presses du reel, 2015.

${ }^{6}$ Versão revisada de: HARAWAY, Donna. In: TSING, Anna Lowenhaupt (edit.). Arts of living on a damaged planet: stories from Anthropocene. Minnesota: Univ. of Minnesota Press, 2016.
} 
holoentes e não indivíduo para referir-se às entidades simpoiéticas, agentes que existem uns com outros. Exemplifica esses processos simpoiéticos com os arrecifes de corais, as selvas dos oceanos ameaçadas pelo aumento da temperatura e acidificação das águas. A relevância de slogans e denominações potentes é retomada em "Generar parentesco. Antropoceno, Capitaloceno, Plantacionoceno, Chthuloceno"7. Nesse quarto capítulo a autora insiste sobre as relações de escala e velocidade que podem indicar o grau para as mudanças das espécies. Considera Capitaloceno uma denominação mais precisa que Antropoceno por assinalar o sistema econômico que vem configurando a destruição ecológica. Plantacionoceno seria uma designação problemática, pois apagaria o trabalho realizado nas hortas dos refúgios de pessoas escravizadas - quilombos - que, sob diferentes modos de associação, promoveram a biodiversidade de plantas, animais, fungos e tipos de solos, mesmo nas adversas circunstâncias do regime de exploração colonial das plantações.

Em "Inundada de orina. DES y Premarin en respons-habilidad multiespecies"8, Haraway nos incita a pensar sobre as histórias que não contamos a respeito da ferocidade praticada aos animais pela indústria de carne e farmacêutica, sobre o inexorável aumento de tratamentos hormonais para a nossa suposta qualidade de vida. O que tem nos impedido de ver/pensar sobre os efeitos do uso conjugado de hormônios naturais e sintéticos em corpos humanos já empapados pela urina de éguas, entre outros bichos? Terraformar é a palavra-chave do sexto capítulo, "Sembrar mundos", no qual fabula com distopias da SF, como as da afrofuturista Octavia Butler (1947-2006). A partir do espetáculo simpoiético de acácias e formigas, especula sobre como lidamos com a terra, e as possibilidades de nos desapegarmos de uma performance fundamentada na metáfora ferramenta/arma/palavra, produtora do relato do caçador imbuído da missão de matar e depredar.

Comprometer-se com o posicionamento epistemológico da virtude da amabilidade é o convite da autora em "Una práctica curiosa"10. Nesse capítulo se fazem presentes Virginia Woolf (1882-1941), Hanna Arendt (1906-1975), Vinciane Despret, Thelma Rowell, entre outras, para reempreender a múltipla e incessantemente reinventada aventura de um relato sobre uma base coletiva e não individual. Por fim, o último e inédito capítulo intitulado "Histórias de Camille. Niñas y niños del compost" apresenta a experiencia de Haraway em uma oficina de escrita criativa, na qual the foi solicitado fabular sobre a vida de um bebê que, de algum modo, seria acompanhado por cinco gerações humanas. Camille é esse bebê, gerado em uma comunidade de compostagem, que não quer saber nada dos gêneros convencionais, nem da excepcionalidade humana, pois nasceu para a simpoiesis, para devir-com. O núcleo da educação de Camille é o aprender a viver em simbiose, criar o animal simbionte, inventar práticas de cuidado com seres simbióticos estendidos.

A leitura de Seguir con el problema. Generar parentesco en el Chthuluceno requer que nos apropriemos de um vocabulário outro para acompanhar o trabalho que, crítica e ironicamente, Donna Haraway vem alargando sobre os limites das figuras que ela metamorfoseia ao longo do seu ciclo ideário. Não se nasce mulher, não se nasce Ciborgue, nem Camille. Seguir com o problema é um desafio ao nosso devir com micróbios, insetos, pessoas, dispositivos tecnológicos em uma terra prenhe de resíduos do lodo produzido no Capitaloceno. É um convite a terraformar, tornar-nos, sem inocência, parentes, compostos, adubo; adotar a virtude da amabilidade e gentileza nas composteiras quentinhas, sem deixar de ver, explicitar e contestar as cálidas relações de poder.

\section{Referências}

GANE, Nicholas; HARAWAY, Donna. "Se nós nunca fomos humanos, o que fazer?". Ponto Urbe, 26, 2010. Disponível em: https://journals.openedition.org/pontourbe/1635?lang=en\#toctoln1. Acesso em: 10/07/2020.

HARAWAY, Donna. "O Humano numa Paisagem Pós-Humanista". Revista Estudos Feministas, Florianópolis, v. 1, n. 2, p. 277-292, jan. 1993. Disponível em: https://periodicos.ufsc.br/index.php/ ref/article/view/16064. Acesso em: 10/07/2020.

7 Versão revisada de: HARAWAY, Donna. Anthropocene, Capitalocene, Plantationocene, Chthulucene: Making Kin. Environmental Humanities, v. 6, n. 1, p. 159-165, 2015. Tradução para o português, de Susana Dias, Mara Verônica e Ana Godoy - Antropoceno, Capitaloceno, Plantationoceno, Chthuluceno: fazendo parentes. ClimaCom - Vulnerabilidade, Campinas, ano 3, n. 5, 2016. Disponível em: http://climacom.mudancasclimaticas.net.br/ antropoceno-capitaloceno-plantationoceno-chthuluceno-fazendo-parentes/. Acesso em: 10/07/2020.

8 Versão revisada de: HARAWAY, Donna. Awash in Urine: DES and Premarin ${ }^{\circledR}$ in Multispecies Response-ability. WSQ, Women's Studies Quarterly, v. 40, n. 1 \& 2, p. 301-316, 2012.

9 Versão revisada de: HARAWAY, Donna. In: GREBOWICZ, Margret; MERRICK, Helen. Beyond the Cyborg: Adventures with Donna Haraway. Nova York: Columbia University Press, 2013.

10 Versão revisada de: HARAWAY, Donna. A curious practice. Angelaki, v. 20, n. 2, p. 5-14, 2015. 
HARAWAY, Donna. "Saberes localizados: a questão da ciência para o feminismo e o privilégio da perspectiva parcial”. Cadernos Pagu (5), p. 7-41, 1995. Disponível em: https://periodicos.sbu. unicamp.br/ojs/index.php/cadpagu/article/view/1773. Acesso em: 10/07/2020.

HARAWAY, Donna. "Manifesto Ciborgue". In: HARAWAY, Donna; KUNZRU, Hari; TADEU, Tomaz (Orgs.). Antropologia do ciborgue: As vertigens do pós-humano. Belo Horizonte: Autêntica, 2000. p. $33-$ 117.

HARAWAY, Donna. "Gênero para um dicionário marxista: a política de uma palavra". Cadernos Pagu. n. 22, p. 201-246, 2004. Disponível em: https://periodicos.sbu.unicamp.br/ojs/index.php/ cadpagu/article/view/8644638. Acesso em: 10/07/2020.

HARAWAY, Donna. "Fragmentos: quanto como uma folha". Mediações. Londrina, v. 20, n. 1, p. 48-68, jan.-jun., 2015. Disponível em: http://www.uel.br/revistas/uel//index.php/mediacoes/article/ view/23252. Acesso em: 10/07/2020.

HARAWAY, Donna. "O Manifesto das espécies companheiras". In: BRANDÃO, Izabel; CAVALCANTI, Ildney; COSTA, Claudia de Lima; LIMA, Ana Cecília. Traduções da Cultura: Perspectivas Críticas Feministas 1970-2010. Florianópolis: Editora Mulheres, 2017. p. 722-745.

HARAWAY, Donna; AZERÊDO, Sandra. "Companhias multiespécies nas naturezaculturas: uma conversa entre Donna Haraway e Sandra Azerêdo". In: MACIEL, Maria Esther (Org.) Pensar/ escrever o animal: ensaios de zoopoética e biopolítica. Florianópolis: EdUFSC, 201 1. p. 389-417.

HARAWAY, Donna. Seguir con el problema. Generar parentesco en el Chthuluceno. Trad. de Helen Torres. Bilbao: Edición Consonni, 2019.

SHELLEY, Mary. O último homem. Trad. de Marcella Furtado. São Paulo: Landmark, 2007.

Fernanda S. Nascimento (fsardelich@gmail.com) é doutora em Psicologia pela Universidade Federal de Pernambuco (UFPE), bolsista da Fundação de Amparo à Ciência e Tecnologia do Estado de Pernambuco (FACEPE), e Mestra em Psicologia também pelo Programa de Pós-Graduação em Psicologia da UFPE. Professora do Mestrado Profissional em Gestão Empresarial do Centro Universitário UniFBV/Wyden. Pesquisa nas áreas de psicologia social, gênero, violência relacional, juventude e sexualidade.

Maria Emilia Sardelich (emisardelich@gmail.com) é doutora em Educação, pela Universidade Federal da Bahia (UFBA). Professora adjunta da Universidade Federal da Paraíba (UFPB), Centro de Educação (CE). Pesquisadora permanente do Programa Associado de PósGraduação em Artes Visuais da UFPB e Universidade Federal de Pernambuco (UFPE). Líder do Grupo de Pesquisa Ensino em Artes Visuais (GPEAV/UFPB). 
COMO CITAR ESTE ARTIGO DE ACORDO COM AS NORMAS DA REVISTA

NASCIMENTO, Fernanda S.; SARDELICH, Maria Emilia. "De pandemias e compostagens: gerando parentescos sem inocência". Revista Estudos Feministas, Florianópolis, v. 29, n. 2, e76043, 2021.

\section{CONTRIBUIÇĀO DE AUTORIA}

Fernanda S. Nascimento - Concepção, coleta, análise, redação da resenha.

Maria Emilia Sardelich - Concepção, coleta, análise, redação da resenha.

\section{FINANCIAMENTO}

Não se aplica.

\section{CONSENTIMENTO DE USO DE IMAGEM}

Não se aplica

\section{APROVAÇĀo DE COMITÊ DE ÉTICA EM PESQUISA}

Não se aplica.

\section{CONFLITO DE INTERESSES}

Não se aplica.

\section{LICENÇA DE USO}

Este artigo está licenciado sob a Licença Creative Commons CC-BY 4.0 International. Com essa licença você pode compartilhar, adaptar, criar para qualquer fim, desde que atribua a autoria da obra.

\section{HISTÓRICO}

Recebida em 29/07/2020

Aprovada em 17/08/2020 